\title{
Determination of Suitable Deficit Irrigation Stage in Potato Production
}

\author{
Shi Xiaohua ${ }^{1,2, \dagger}$, Jia Liguo ${ }^{1, \dagger}$, Yang Haiying ${ }^{2}$, Wu Lan $^{1}$, Qin Yonglin ${ }^{1}$, Fan Mingshou ${ }^{1, *}$ \\ ${ }^{1}$ College of Agronomy, Inner Mongolia Agricultural University, Hohhot, China \\ ${ }^{2}$ Inner Mongolia Propagation Center of Virus-free Seed Potato, Hohhot, China \\ Email address: \\ 13451349668@126.com (Shi Xiaohua),nndjialiguo@163.com (Jia Liguo),fmswh@126.com (Fan Mingshou) \\ *Corresponding author \\ $\uparrow$ Shi Xiaohua and Jia Liguo are co-first authors.
}

To cite this article:

Shi Xiaohua, Jia Liguo, Yang Haiying, Wu Lan, Qin Yonglin, Fan Mingshou. Determination of Suitable Deficit Irrigation Stage in Potato Production. Journal of Plant Sciences. Vol. 9, No. 5, 2021, pp. 262-271. doi: 10.11648/j.jps.20210905.15

Received: September 7, 2021; Accepted: September 26, 2021; Published: October 12, 2021

\begin{abstract}
Water deficiency is the major limiting factor for potato yield promotion. Increasing tuber yield and decreasing consumption of water at the same time are a challenge in development of new potato cultivar. Deficit irrigation is regarded as one of the promising approaches to solve this problem, however no practical technique has been proposed in potato production as yet. By setting different deficient irrigation regimes and investigating potato growth and water use efficiency, we found that only application of deficit irrigation at the seedling stage could achieve the goal of increasing water use efficiency and maintaining marketable tuber yield at the same time. Almost half of the normal full irrigation doubled promotion effects on water efficiency and yield, especially the marketable tuber yield. This may be mainly attributed to establishment of a strong root system, including longer root length and larger root surface area under water deficit at the seedling stage. Based on such a root system at the early development stage, leaf area index and dry matter accumulation were optimized at the later developmental stages. Thus, maintaining water deficit at the seedling stage with enough water supplied at the tuber initiation and bulking stages should be practiced in potato production in water limited areas.
\end{abstract}

Keywords: Potato, Growth Stage, Water Stress, Deficit Irrigation

\section{Introduction}

Potato ranks behind wheat, maize and rice as the fourth most important food crop in the world [1]. In 2019, 104.67 megatons of potato were produced within 17.34 million hectares world-wide [2]. Although the planting area and yield increased gradually in past twenty years, continuous population increase and uncertainties of climate change challenge potato production [3]. Climate change has accounted for $18-23 \%$ yield losses of potato in the first three decades of this century. Among all environmental factors, water deficiency is a major factor limiting potato production and quality $[4,5]$.

Potato is sensitive to water stress due to its shallower and less dense root distribution in the field compared with other field crops, moreover, its low capacity of recuperation after water stress makes its drought vulnerable [6]. Opena and
Porter (1999) showed that approximately $85 \%$ of the root mass is concentrated on the upper $0.3 \mathrm{~m}$ soil layer [7]. Extensive negative effects on yield production including the number of tuber per plant, tuber size, quality and final yield are exhibited when a potato crop faces water stress $[4,8]$. However, dietary energy conversion efficiency of potato per drop water is the highest among major crops, it produces 5600 kcal dietary energy for every cubic meter water applied, only $3860 \mathrm{kcal}$ in maize, $2300 \mathrm{kcal}$ in wheat and $2000 \mathrm{kcal}$ in rice under same condition [9]. Therefore, potato might play more and more important role on ensuring world food security in the future. However, with the extension of potato cultivation in drought prone areas the impacts of water restriction on potato production will likely increase over the next decades.

Deficit irrigation (DI) and controlled alternate partial root-zone irrigation are gradually considered to be two promising water-saving techniques $[10,11]$. Moderate water deficit may not necessarily reduce yield, while improving water use efficiency 
(WUE), as has been demonstrated in several crops [12]. In addition, the mechanisms by which moderate water deficit is able to increase water use efficiency but maintain or even increase crop yield have been investigated [13, 14]. Fully irrigated plants usually keep the stomata opened widely which results in heavy water consumption, In contrast, when plants sense the soil drying, stomatal openings are narrowed and water loss is substantially reduced with little effect on photosynthesis $[12,15]$. As the root oriented signal, ABA regulates stomatal behavior [16]. This phenomenon has also been demonstrated in potato [17-19]. Moreover, ABA induced by soil drying plays an important role in the promotion of a larger number of tubers and earlier tuberization [20].

However, effects under deficit irrigation influenced by soil texture, intensity and developmental stage born water deficiency, etc. By controlling the irrigation amount at whole developmental stages, Onder et al (2005) found that water deficiency of less than $33 \%$ did not result in a decrease in potato tuber yield but significantly increased water use efficiency [8]. Nevertheless, under Mediterranean climate conditions, off-season potato at moderate water deficit showed increased tuber growth and consequently tuber yield compared to a well-watered control [21]. Field experiments for potato proved that DI and partial root zone drying irrigation (PRD), saved 20-30\% water compared to full irrigation. Moreover, PRD technology could increase marketable potato tuber yield by $15 \%$ because of the amelioration in tuber size distribution [22]. Soil texture also affects the use of water-saving technologies such as DI and PDR practices. It has good effects in sandy loam and coarse sand but dramatically reductions in potato yield occurred under loamy sand condition [23].

Selecting appropriate irrigation scheduling is necessary for deficit irrigation strategy, and a sensitive stage of the crop need to avoid. Iqbal et al (1999) considered that the most sensitive period to water stress for potato was the early development stage (seedling stage), which resulted in a greatest yield reduction when experienced water stress [24].
The emergence and tuberization stages are two critical periods when final tuber yield is most affected by water stress [6]. Yactayo et al (2013) found that DI practices at six and eight weeks after planting with $50 \%$ of water restriction, did not change water use efficiency, but significantly decreased the yield [11].

However, suitable developmental stage for deficit irrigation in potato is still unclear. The objectives of this study were to select an optimal stage for DI practice by comparing effects of DI at different potato developmental stages in Yin-mountain hilly area of China, where is the advantageous region of country potato production but water deficiency is a key limiting factor. After optimized developmental stage(s) suitable for DI then irrigation quotas was tested, best irrigation regime was built finally under deficit irrigation of potato. The work is very important to develop local potato production and agricultural sustainable development under the condition of water resource deficiency.

\section{Materials and Methods}

\subsection{Plant Materials and Cultivation}

Field experiments were conducted at a research farm of Inner Mongolia Agricultural University, Hohhot, China $\left(41^{\circ} 16^{\prime} \mathrm{N}, 111^{\circ} 30^{\prime} \mathrm{E}\right)$ during the potato growing season (May-October) in 2018 2019. The mean photosynthetically active radiation (PAR) was approximately $1.83 \times 10^{6} \mathrm{KJ} / \mathrm{m}^{2}$ and the mean temperature was $14.2^{\circ} \mathrm{C}$ during potato growth season. The total precipitation during the growth season was $226.3 \mathrm{~mm}$ in 2018 and $282.30 \mathrm{~mm}$ in 2019 at the experiment site. In 2020, the experiment was implemented in a rain shelter to avoid rainfall effect. Soil texture of the experimental fields is sandy loam; its sand, silt and clay contents are approximately $50 \%, 30 \%$, and $14 \%$ respectively; additionally, it has $6 \%$ of gravel (larger than $2 \mathrm{~mm}$ in size). Detailed soil properties of the experimental sites are shown in Table 1.

Table 1. Properties of the soil (top 20cm) at the experimental sites.

\begin{tabular}{|c|c|c|c|c|c|c|}
\hline Year & pH & Field water-holding capacity (\%) & Organic matter $(\mathrm{g} / \mathrm{kg})$ & Total nitrogen $(\mathrm{g} / \mathrm{kg})$ & Olsen-P (mg/kg) & Exchangeable K (mg/kg) \\
\hline 2018 & 8.06 & 23.37 & 13.06 & 1.37 & 10.42 & 108.1 \\
\hline 2019 & 8.21 & 23.53 & 13.54 & 1.30 & 14.20 & 128.3 \\
\hline 2020 & 8.21 & 23.94 & 15.59 & 0.72 & 38.48 & 193.7 \\
\hline
\end{tabular}

Nitrogen was measured by Kjeldah method, and Olsen-P $\left.(0.5 \mathrm{M} \mathrm{NaHCO})_{3}\right)$ and exchangeable $\mathrm{K}\left(\mathrm{NH}_{4} \mathrm{OAc}\right)$ were analyzed using the method of Sparks et al [25]. Potassium Dichromate Volumetric Method was used for soil organic matter determination and the soil $\mathrm{pH}$ values were analyzed by $\mathrm{pH}$ meter. The field water holding capacity and bulk density were measured after constant drainage rate and made gravimetrically.

The virus-free seed potato (Solanum tuberosum L.) cultivars, Favorita and Kexin No. I, were used in the trials in 2018 and 2019, respectively, both the two cultivars were used in 2020 . The experimental plot was $12 \mathrm{~m} \times 6 \mathrm{~m}$ with $0.5 \mathrm{~m}$ row spacing and $0.4 \mathrm{~m}$ plant spacing. The soil was ridged to $10 \mathrm{~cm}$ above the seed tubers with total $20 \mathrm{~cm}$ ridge height. The fertilizer contained $\mathrm{N}$ (180 kg.ha ${ }^{-1}$ as urea), $\mathrm{P}_{2} \mathrm{O}_{5}\left(130 \mathrm{~kg} \cdot \mathrm{ha}^{-1}\right.$ as single superphosphate) and $\mathrm{K}_{2} \mathrm{O}\left(150 \mathrm{~kg} \cdot \mathrm{ha}^{-1}\right.$ as $\left.\mathrm{KCl}\right)$ during sowing (18 May) in 2018, N (247 kg.ha $\left.{ }^{-1}\right), \mathrm{P}_{2} \mathrm{O}_{5}(180$ kg.ha $\left.{ }^{-1}\right)$, and $\mathrm{K}_{2} \mathrm{O}$ (264 kg.ha $\left.{ }^{-1}\right)$ were used during sowing (10 May) in 2019, and $\mathrm{N}\left(536 \mathrm{~kg} \cdot \mathrm{ha}^{-1}\right), \mathrm{P}_{2} \mathrm{O}_{5}\left(375 \mathrm{~kg} \mathrm{ha}^{-1}\right)$, and $\mathrm{K}_{2} \mathrm{O}$ (750 kg.ha ${ }^{-1}$ ) were used during sowing (15 May) in 2020.

\subsection{Treatments}

Water deficiency treatments were set in four developmental stages in both 2018 and 2019, which were laid out in a 
completely randomized block design with three replications. The protection area between plots was set $2 \mathrm{~m}$ wide to avoid border effects and water side leakage. The treatments included full irrigation (FI), deficit irrigation at seedling stage (DIS), deficit irrigation at tuber initiation stage (DII) and deficit irrigation at tuber bulking stage of potato (DIB). DIS, DII and DIB only conduct deficit irrigation at corresponding specific growth stage as described above, while full irrigation were applied during other growth stages of potato.

The irrigation quotas at different developmental stages were applied under full irrigation according to previous studies [5, 26], that is $65 \%, 70 \%, 75 \%$ and $60 \%$ relative soil water content at seedling stage, tuber initiation stage, tuber bulking stage and maturation stage of potato, respectively. In 2018, irrigation quotas under DI treatments were halves of full irrigation at same developmental stages, no matter what was the soil water condition. In order to allocate available water in soil accurately, irrigation quotas were controlled by relative soil water content in 2019, 55\% (DIS1) and 45\% (DIS2) RWC at the seedling stage, $60 \%(\mathrm{DII})$ and $65 \%(\mathrm{DIB}) \mathrm{RWC}$ at the tuber initiation stage and tuber bulking stage were set, respectively. To suppress rainfall interference during experiment another trial was performed under rain shelter condition in 2020. Based on the results in 2018 and 2019 on two deficit irrigation treatments at seedling stage of potato, $50 \%$ RWC (DIS3) and 35\% RWC (DIS4), were set.

Drip irrigation method was used, and irrigation amount for each treatment based on Marsal et al. (2008) as list in table 2 [27]. Drip type was placed in the center of the ridge; the inside diameter of drip tape was $16 \mathrm{~mm}$, the distance between two emitters were $30 \mathrm{~cm}$ and each emitter $(2.0 \mathrm{~L} / \mathrm{h})$ was the midway between two plants. In 2019, allowed deviation of RWC was 5\% for a specific treatment, eg. aimed RWC was $60 \%$ at the seedling stage, if the tested value of $0-60 \mathrm{~cm}$ soil layer was lower than 55 60\% applied irrigated water to $65 \%$ RWC. Then, relative soil water content were detected every three days by drying method as described below, while the value is lower than the thereshold another irrigation supplied. In 2020, the allowed deviation of RWC was controlled within $2 \%$, same detection method of soil water content was used.

Table 2. The irrigation regime under four treatments ( $\mathrm{mm}$ ). FI, DIS, DII and DIB stand for treatments of full irrigation, deficit irrigation at seedling stage, deficit irrigation at tuber initiation stage and deficit irrigation at tuber bulking stage respectively. In 2019, one more treatment was appended at seedling stage in which DIS1 and DIS2 stand for 55\% and 45\% lower limit of relative soil water content (RWC). Two deficit irrigation treatments at seedling stage of potato, 50\% RWC (DIS3) and 35\% RWC (DIS4), were set in 2020.

\begin{tabular}{|c|c|c|c|c|c|c|}
\hline \multirow{2}{*}{$\begin{array}{l}\text { Year } \\
\text { Cultivar }\end{array}$} & \multirow{2}{*}{$\begin{array}{l}\text { Irrigation } \\
\text { treatments }\end{array}$} & \multicolumn{4}{|c|}{ Developmental stages } & \multirow{2}{*}{$\begin{array}{l}\text { Total irrigation } \\
\text { amount }\end{array}$} \\
\hline & & Seedling & Tuber initiation & Tuber bulking & Maturation & \\
\hline \multirow{4}{*}{2018 Favorita } & FI & 18 & 54 & 90 & 18 & 180 \\
\hline & DIS & 9 & 54 & 90 & 18 & 171 \\
\hline & DII & 18 & 27 & 90 & 18 & 153 \\
\hline & DIB & 18 & 54 & 45 & 18 & 135 \\
\hline \multirow{5}{*}{2019 Kexin No.1 } & FI & 22 & 50 & 73 & 13 & 158 \\
\hline & DIS1 & 17 & 48 & 71 & 8 & 145 \\
\hline & DIS2 & 8 & 49 & 68 & 5 & 131 \\
\hline & DII & 22 & 34 & 69 & 9 & 134 \\
\hline & DIB & 22 & 50 & 39 & 7 & 117 \\
\hline \multirow{3}{*}{2020 Favorita } & FI & 71 & 166 & 242 & 6 & 487 \\
\hline & DIS3 & 35 & 113 & 169 & 12 & 329 \\
\hline & DIS4 & 8 & 49 & 90 & 8 & 166 \\
\hline \multirow{3}{*}{2020 Kexin No. 1} & FI & 71 & 165 & 241 & 57 & 536 \\
\hline & DIS3 & 41 & 134 & 200 & 65 & 438 \\
\hline & DIS4 & 15 & 116 & 162 & 60 & 354 \\
\hline
\end{tabular}

\subsection{Sampling and Measurements}

The relative water contents of soil. Soil samples were taken by an auger at the midpoint between potato seedlings from the top $60 \mathrm{~cm}$ layer of soil. Five replications were conducted for each treatment. After weighing, soil samples were dried in an oven set to $105{ }^{\circ} \mathrm{C}$ until constant weight was obtained for determination of weight based water content. The percentage of actual water content account for field water-holding capacity expressed as relative water content $(\%)$. In order to understand the water dynamics in drip-irrigated potato field in silico approach was used. Three points $(1 \mathrm{~d}, 4 \mathrm{~d}$ and $7 \mathrm{~d}$ after irrigation) in one irrigation cycle in 2018 were selected for simulation via Kriging model using Sigma Plot software in our study (Figure 1).

Leaf area index was determined with a leaf area meter (Model LI-3100, LI-COR, Inc., Lincoln, NE) during whole developmental period in 2018, 2019 and 2020. The leaf area index was calculated as leaf area per unit ground area.

Root system characteristics determination began with root collection referred to Costa et al method [28]. After stem was cut off the soil mixture surrounding its position was collected in 0-10, 10-20, 20-30, 30-40, 40-50 and 50-60 cm, respectively. The samples were immersed in a water-filled container first, then spraying with water until it was almost free of soil particles. The roots connected to the stem were separated and the fine roots in the water solution were picked out by forceps as complete as possible. The total roots were kept fully immersed in a $35 \%$ ethanol solution waiting for investigation. Before scanning the roots were stained for $15 \mathrm{~min}$ with $0.1 \%$ $(\mathrm{w} / \mathrm{v})$ toluidine blue. Root measurements were performed using WinRHIZO (Reagent Instrument Inc., Quebec, Canada), the root length, surface area and volumn were analyzed and recorded. Root analysis was only conducted in 2018. 

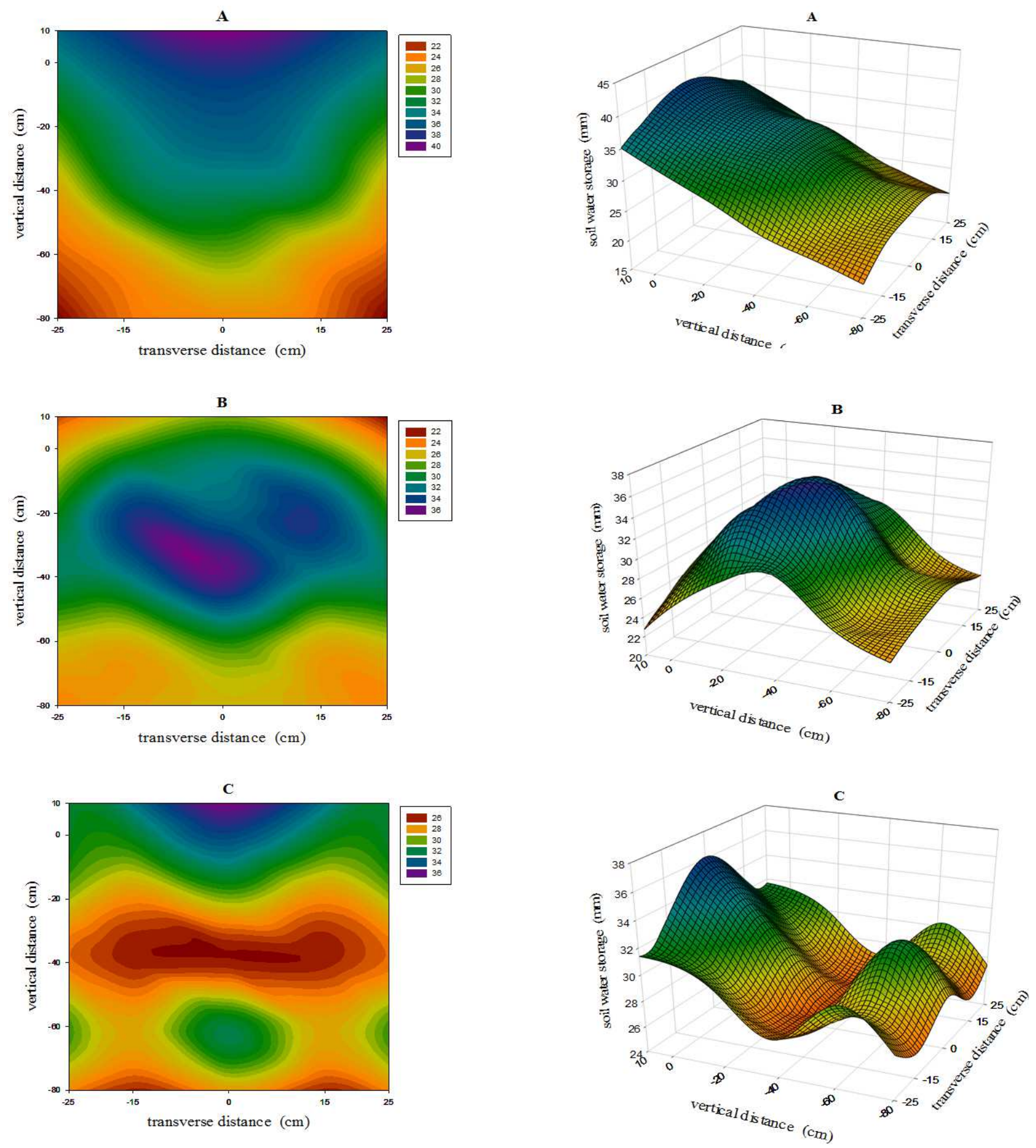

Figure 1. The contour map and $3 D$ wire frame map of soil water storage at the (A) first day, (B) fourth day and (C) seventh day after drip irrigation. Sigma Plot (version 2.0) was used for simulate.

Dry matter was measured by Oven-drying method. Three plants per plot were harvest for the determination. After separating the leaf, shoot, root, stolon and tuber from one plant, the samples were dried at $105^{\circ} \mathrm{C}$ for $30 \mathrm{~min}$ and then $80^{\circ} \mathrm{C}$ for 12-24h.

Yield harvest were made on 20 September in 2018, 11 September in 2019, 17 August for Favorita and 13 September for Kexin No. I in 2020, two square meters (except for border plants) per plot was randomly selected and harvested for yield determination, three times repeated. Fresh tubers were graded into $<50 \mathrm{~g}$ and $>150 \mathrm{~g}$ for fresh weight per tuber and dry weight of sliced tubers for detection. Larger than $150 \mathrm{~g}$ fresh weight per tuber were recorded as marketable tuber. Tuber numbers per plant were recorded during determination.

Water use efficiency of each irrigation treatment was calculated by dividing total tuber fresh weight $\left(\mathrm{kg} \mathrm{ha}^{-1}\right)$ by actual evapotranspiration ( $\mathrm{mm}$ ) during whole growth period. Actual evapotranspiration within the growth period was estimated from the soil water balance equation as follows: 


$$
\mathrm{ET}=\mathrm{I}+\mathrm{P}-\mathrm{D}+\Delta \mathrm{S}
$$

Where ET is actual crop evapotranspiration ( $\mathrm{mm})$, I is depth of applied irrigation water $(\mathrm{mm}), \mathrm{P}$ is precipitation $(\mathrm{mm}), \mathrm{D}$ is deep percolation or drainage below the root zone $(\mathrm{mm}), \Delta \mathrm{S}$ is soil water depletion at harvest, expressed as the difference between soil water content values in $0-60 \mathrm{~cm}$ soil depth at planting and at the end of harvesting ( $\mathrm{mm})[23]$. Because the rainfall was low and over irrigation was controlled to avoid in the experimental years, D was neglected in this study. Water use efficiency (WUE) considered all of the above elements and was calculated as below.

\section{WUE $(\mathrm{kg} / \mathrm{ha} / \mathrm{mm})=$ Yield $/ \mathrm{ET}$}

\subsection{Statistical Analyses}

The results were analyzed for variance using the SPSS statistical analysis package (version 19.0). Means were tested by least significant difference at the $\mathrm{P}=0.05$ level $\left(\mathrm{LSD}_{0.05}\right)$. Sigma Plot (version 2.0) was used to simulate the soil water dynamics.

\section{Results}

\subsection{Water Dynamics of Soil at Spatial and Temporal Scales Under Different Irrigation Treatments}

To clear and definite the water status in experimental soil, relative water contents (RWC) were detected at 0-20, 20-40 and $40-60 \mathrm{~cm}$ soil layers throughout the potato developmental stages. Under full irrigation (FI) conditions, the relative water contents at $0-60 \mathrm{~cm}$ soil were $60-67 \%$ at the seedling, $66-85 \%$ at tuber initiation stage, and $69-76 \%$ at tuber bulking and $42-54 \%$ at the maturation stages in 2018 (Table 3). In 2019, $65 \pm 5 \%, 70 \pm 5 \%, 75 \pm 5 \%$ and $60 \pm 5 \%$ relative soil water content was controlled in full irrigation at seedling stage, tuber initiation stage, tuber bulking stage and maturation stage of potato, respectively. Keeping the same irrigation regime except for $55 \pm 5 \%$ and $45 \pm 5 \%$ RWC at seedling stage in DIS 1 and DIS2 treatments, $60 \%$ and $65 \%$ RWC at the tuber initiation stage and tuber bulking stage in DII and DIB treatments, respectively. It was $50 \pm 2 \%$ and $35 \pm 2 \%$ RWC controlled at seedling stage in DIS3 and DIS4 treatments respectively in 2020 .

Table 3. Relative soil water content (\%) at different developmental stages of potato under four irrigation treatments in 2018. FI, DIS, DII and DIB stand for treatments of full irrigation, deficit irrigation at seedling stage, deficit irrigation at tuber initiation stage and deficit irrigation at tuber bulking stage respectively. Data are means \pm standard error of five independent measurements.

\begin{tabular}{|c|c|c|c|c|c|c|c|c|c|}
\hline \multirow{3}{*}{ Treatments } & \multirow{3}{*}{$\begin{array}{l}\text { Soil depth } \\
\text { (cm) }\end{array}$} & \multicolumn{8}{|c|}{ Developmental stages (Month/Day) } \\
\hline & & \multirow{2}{*}{$\begin{array}{l}\text { Sowing } \\
(5 / 18)\end{array}$} & \multirow{2}{*}{$\begin{array}{l}\text { Seedling } \\
(7 / 9)\end{array}$} & \multicolumn{2}{|c|}{ Tuber initiation } & \multicolumn{3}{|c|}{ Tuber bulking } & \multirow{2}{*}{$\begin{array}{l}\text { Maturation } \\
(9 / 6) \\
\end{array}$} \\
\hline & & & & $(7 / 15)$ & $(7 / 21)$ & $(7 / 26)$ & $(8 / 2)$ & $(8 / 22)$ & \\
\hline \multirow{3}{*}{ FI } & $0-20$ & $57.6 \pm 0.8$ & $60.9 \pm 0.4$ & $72.6 \pm 0.8$ & $66.0 \pm 0.5$ & $76.6 \pm 0.1$ & $75.1 \pm 0.9$ & $69.0 \pm 1.1$ & $42.4 \pm 1.4$ \\
\hline & $20-40$ & $65.0 \pm 1.0$ & $64.1 \pm 0.3$ & $78.1 \pm 0.02$ & $68.5 \pm 0.3$ & $73.8 \pm 0.3$ & $75.3 \pm 0.1$ & $70.4 \pm 0.5$ & $44.9 \pm 1.3$ \\
\hline & $40-60$ & $60.9 \pm 1.5$ & $67.3 \pm 1.3$ & $85.6 \pm 2.4$ & $77.8 \pm 2.4$ & $72.8 \pm 0.5$ & $76.9 \pm 0.1$ & $73.9 \pm 0.7$ & $54.5 \pm 0.5$ \\
\hline \multirow[b]{2}{*}{ DIS } & $0-20$ & $59.2 \pm 0.5$ & $50.7 \pm 0.4$ & $71.2 \pm 0.7$ & $65.3 \pm 0.7$ & $76.0 \pm 0.4$ & $73.5 \pm 0.2$ & $70.4 \pm 0.7$ & $45.9 \pm 1.0$ \\
\hline & $20-40$ & $60.4 \pm 1.6$ & $53.0 \pm 0.02$ & $71.9 \pm 0.4$ & $62.9 \pm 2.4$ & $77.6 \pm 0.3$ & $77.1 \pm 0.7$ & $72.2 \pm 0.1$ & $59.7 \pm 0.7$ \\
\hline \multirow{3}{*}{ DII } & $0-20$ & $55.6 \pm 1.0$ & $60.3 \pm 0.1$ & $60.9 \pm 0.7$ & $59.6 \pm 0.3$ & $76.1 \pm 0.2$ & $71.8 \pm 0.2$ & $67.5 \pm 0.3$ & $46.1 \pm 0.8$ \\
\hline & $20-40$ & $55.6 \pm 0.8$ & $60.7 \pm 1.5$ & $61.0 \pm 0.4$ & $53.5 \pm 1.1$ & $75.4 \pm 0.7$ & $74.8 \pm 0.5$ & $70.3 \pm 0.6$ & $54.7 \pm 1.5$ \\
\hline & $40-60$ & $64.8 \pm 0.8$ & $74.4 \pm 0.5$ & $67.9 \pm 1.9$ & $65.7 \pm 3.1$ & $75.9 \pm 2.5$ & $75.5 \pm 1.6$ & $73.7 \pm 1.0$ & $56.6 \pm 0.2$ \\
\hline \multirow{3}{*}{ DIB } & $0-20$ & $56.4 \pm 0.6$ & $57.6 \pm 0.2$ & $72.5 \pm 0.04$ & $64.9 \pm 0.6$ & $64.3 \pm 0.2$ & $62.2 \pm 0.1$ & $63.3 \pm 0.6$ & $44.9 \pm 0.5$ \\
\hline & $20-40$ & $54.5 \pm 1.4$ & $59.0 \pm 0.6$ & $71.9 \pm 0.6$ & $66.9 \pm 0.3$ & $68.9 \pm 0.6$ & $67.5 \pm 0.9$ & $68.4 \pm 0.5$ & $55.5 \pm 0.0$ \\
\hline & $40-60$ & $59.1 \pm 0.4$ & $72.2 \pm 1.0$ & $82.1 \pm 3.3$ & $71.9 \pm 0.2$ & $72.6 \pm 1.5$ & $71.0 \pm 1.7$ & $66.2 \pm 0.9$ & $57.3 \pm 3.1$ \\
\hline
\end{tabular}

To better understand the effects of soil water status on root distribution, water dynamics in irrigation cycle were simulated in 2018. The first day after irrigation water was concentrated in the first $50 \mathrm{~cm}$ of the soil layer directly below the dipper, the farther distance from the dipper position, the lower the water

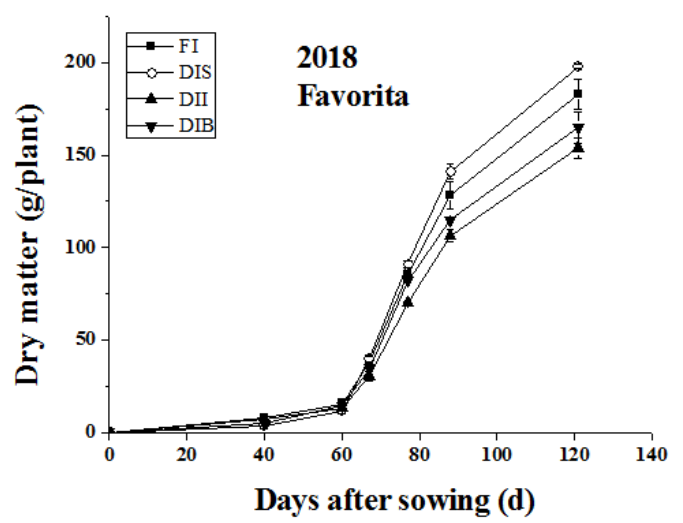

concentration (Figure 1A). With water movement and evapotranspiration aboveground, the irrigation water expanded to $20-70 \mathrm{~cm}$ below the dipper and $0-20 \mathrm{~cm}$ soil layer became dry (Figure 2B). Irrigated water was almost depleted at day 7, especially at the $30-60 \mathrm{~cm}$ below the dipper (Figure 2C).

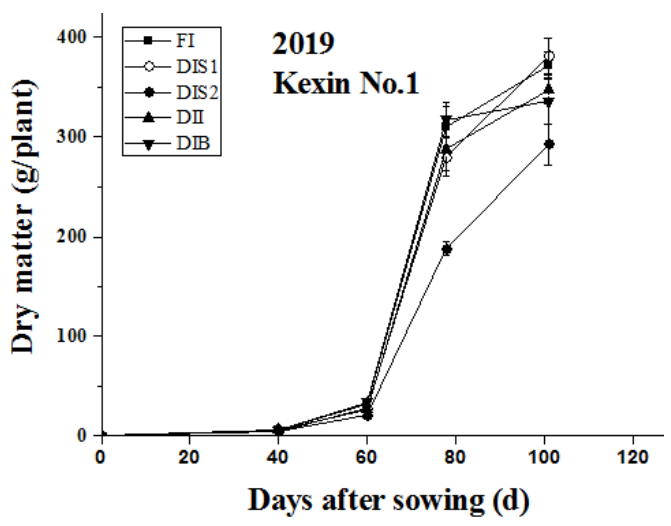



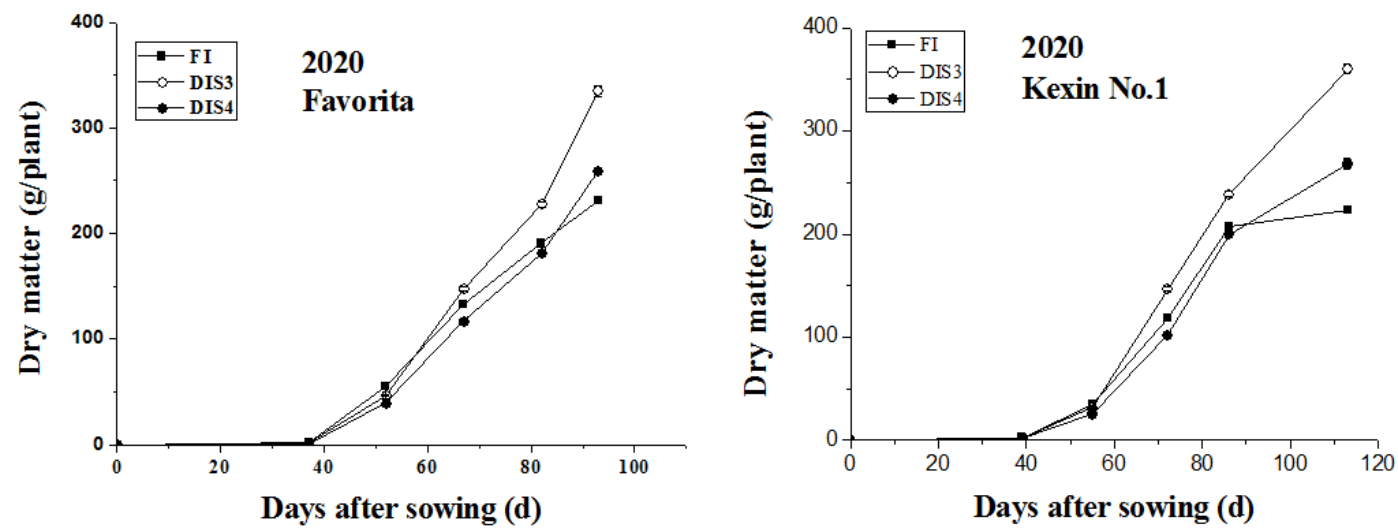

Figure 2. Effect of irrigations on changes of plant dry matter accumulation. FI, DIS, DII and DIB stand for treatments of full irrigation, deficit irrigation at Seedling stage, deficit irrigation at tuber initiation stage and deficit irrigation at tuber bulking stage respectively. DIS1 and DIS2 stand for $55 \%$ and $45 \%$ lower limit of relative soil water content (RWC) at the seedling stage in 2019. DIS3 and DIS4 stand for 55\% RWC and 45\% RWC at the seedling stage of potato in 2020. Data are means \pm standard error of three independent measurements.

\subsection{Root Characteristics of Potato Under Different Irrigation Treatments}

Root characteristics including root length, root surface area, volume and dry matter of root were determined at different layers of $0-60 \mathrm{~cm}$ top soil in 2018 (Table 4). Total root length and root surface area at $0-60 \mathrm{~cm}$ soil layers under deficit irrigation at the seedling stage of potato (DIS) were significantly higher than under the other irrigation treatments. Root volume was also the highest under DIS compared with other three irrigation practices and significantly higher than full irrigation. There was no significantly difference on root dry matter among the four irrigation treatments (Table 4).

No obvious difference was found on root length and surface area among the treatments at 20-40 cm soil layer. The major difference on total root length and surface area was attributed to the differences at $0-20 \mathrm{~cm}$ and $40-60 \mathrm{~cm}$ soil layers. Root volume exhibited the same tendency with root length and surface area among different irrigation treatments (Table 4).

Table 4. Root spatial distribution of potato cultivar Kexin No.1 under different irrigation treatments in 2018. FI, DIS, DII and DIB stand for treatments of full irrigation, deficit irrigation at seedling stage, deficit irrigation at tuber initiation stage and deficit irrigation at tuber bulking stage respectively. Data are means of three independent measurements. Different letters of 0-60 cm data indicate statistical significance at the P=0.05 level within the same column.

\begin{tabular}{|c|c|c|c|c|c|}
\hline \multirow{2}{*}{ Irrigation treatments } & Soil depth & Root length & Surface area & Volume & Dry matter \\
\hline & $(\mathrm{cm})$ & $(\mathrm{cm})$ & $\left(\mathrm{cm}^{2}\right)$ & $\left(\mathrm{cm}^{3}\right)$ & (g) \\
\hline \multirow{9}{*}{ FI } & $0-10$ & 4498.3 & 1482 & 58 & 1.061 \\
\hline & $10-20$ & 4606.8 & 1986 & 107 & 1.488 \\
\hline & $20-30$ & 3187.1 & 1087 & 45 & 0.567 \\
\hline & $30-40$ & 1252.2 & 432 & 18 & 0.327 \\
\hline & $40-50$ & 401.9 & 134 & 5 & 0.165 \\
\hline & $50-60$ & 208.7 & 45 & 2 & 0.089 \\
\hline & $0-60$ & $14155.8 \mathrm{~b}$ & $5165 \mathrm{~b}$ & $234 \mathrm{~b}$ & $3.7 \mathrm{a}$ \\
\hline & $0-10$ & 4571.7 & 1766 & 75 & 1.062 \\
\hline & $10-20$ & 5584.5 & 2141 & 131 & 1.644 \\
\hline \multirow{5}{*}{ DIS } & $20-30$ & 3159.5 & 1043 & 39 & 0.564 \\
\hline & $30-40$ & 1203.1 & 382 & 18 & 0.335 \\
\hline & $40-50$ & 554.9 & 209 & 9 & 0.176 \\
\hline & $50-60$ & 397.4 & 176 & 9 & 0.103 \\
\hline & $0-60$ & $15471.3 \mathrm{a}$ & $5716 \mathrm{a}$ & $285 \mathrm{a}$ & $3.9 \mathrm{a}$ \\
\hline \multirow{9}{*}{ DII } & $0-10$ & 4554.4 & 1527 & 62 & 1.063 \\
\hline & $10-20$ & 4825.5 & 1999 & 117 & 1.635 \\
\hline & $20-30$ & 3077 & 1077 & 41 & 0.552 \\
\hline & $30-40$ & 1252.2 & 391 & 21 & 0.307 \\
\hline & $40-50$ & 502.8 & 145 & 6 & 0.17 \\
\hline & $50-60$ & 349.9 & 105 & 5 & 0.096 \\
\hline & $0-60$ & $14561.7 \mathrm{~b}$ & $5244 \mathrm{~b}$ & $253 \mathrm{ab}$ & $3.8 \mathrm{a}$ \\
\hline & $0-10$ & 4217.6 & 1421 & 54 & 0.994 \\
\hline & $10-20$ & 4675.1 & 1944 & 115 & 1.55 \\
\hline \multirow{5}{*}{ DIB } & $20-30$ & 3346.5 & 1266 & 43 & 0.569 \\
\hline & $30-40$ & 1172.4 & 452 & 23 & 0.312 \\
\hline & $40-50$ & 474.9 & 138 & 5 & 0.176 \\
\hline & $50-60$ & 284.4 & 77 & 4 & 0.087 \\
\hline & $0-60$ & $14170.8 \mathrm{~b}$ & $5298 \mathrm{~b}$ & $244 \mathrm{ab}$ & $3.7 \mathrm{a}$ \\
\hline
\end{tabular}




\subsection{Leaf Area Index and Dry Matter Accumulation Under Different Irrigation Treatments}

The Leaf area index (LAI) was significantly decrease under water deficiency at the seedling, tuber initiation and tuber bulking stage as showed in 2018, which was almost half of that with full irrigation. As the irrigation amount was decreased $10 \%(60 \%$ RWC) at tuber initiation stage the LAI didn't decrease significantly, but it was still lower than full irrigation when $10 \%(65 \%$ RWC) reduced at tuber bulking stage as showed in 2019. As facing severe water deficiency at the seedling stage (35-45\% RWC) LAI reduced significantly compared with full irrigation, however, tolerance cultivar (Kexin No.1) to water stress didn't decrease LAI but it was still reduced for sensitive cultivar (Favorita) based on three-year experimental results (Table 5). Moreover, as seedling experienced water stress at the seedling stage its LAI recovered even surpassed FI treatment as irrigation returned to normal levels at the later developmental stages (Table 5).

Table 5. Leaf area index of cultivar during potato growth period under different irrigation treatments in 2018, 2019 and 2020. FI, DIS, DII and DIB stand for treatments of full irrigation, deficit irrigation at seedling stage, deficit irrigation at tuber initiation stage and deficit irrigation at tuber bulking stage respectively. Data are means \pm standard error of three independent measurements. The same letters in the column show non-significance at 0.05 probability level.

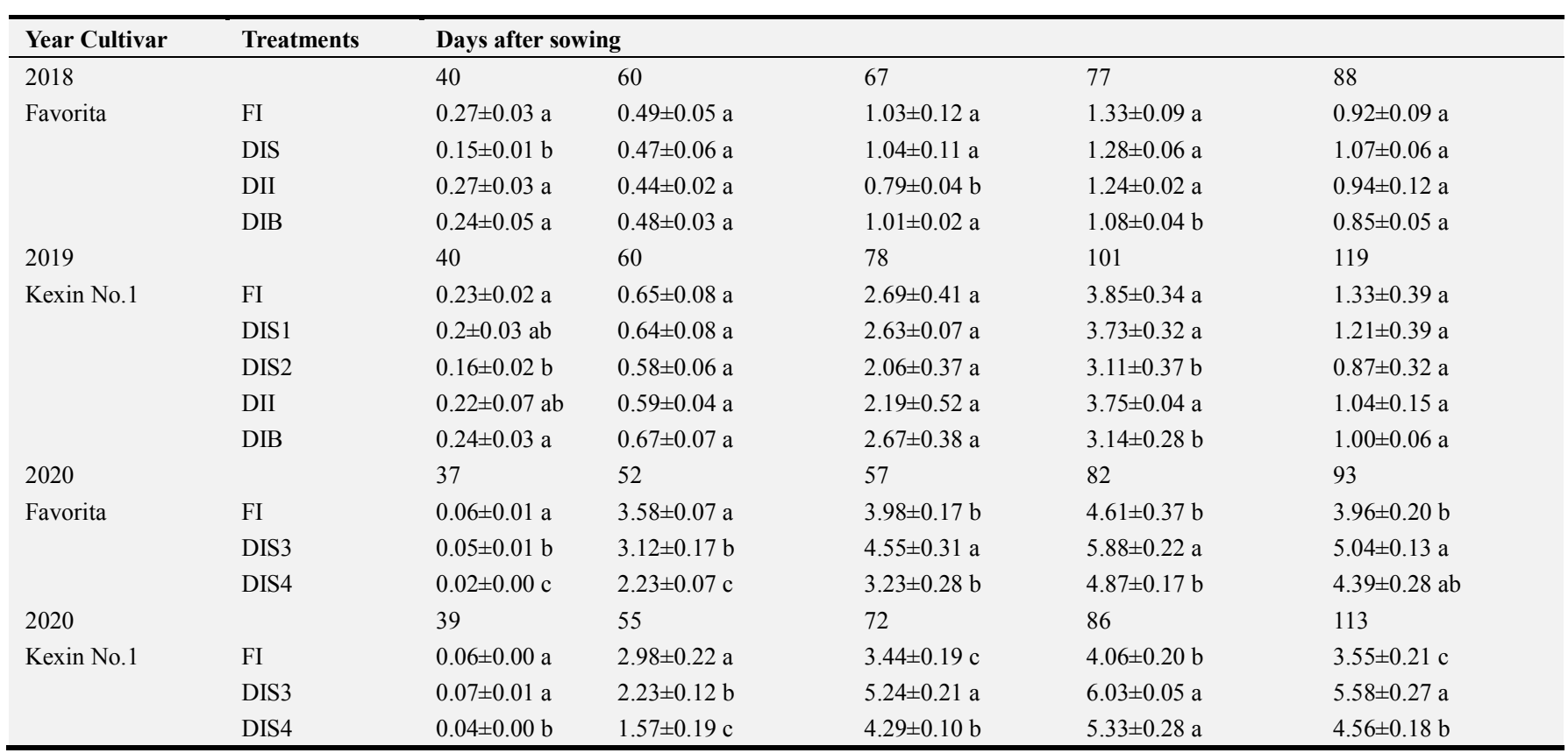

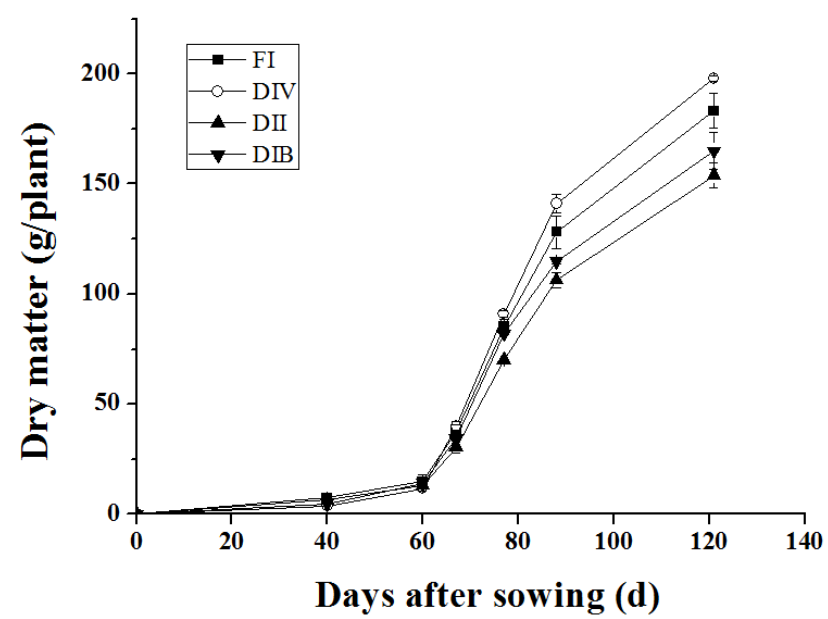

Figure 3. Effect of irrigations on changes of plant dry matter accumulation in 2018. FI, DIS, DII and DIB stand for treatments of full irrigation, deficit irrigation at Seedling stage, deficit irrigation at tuber initiation stage and deficit irrigation at tuber bulking stage respectively. Data are means \pm standard error of three independent measurements.
The pattern of dry matter accumulation was similar to LAI, reduced under water deficiency at the tuber initiation and bulking stages before harvested compared to full irrigation treatment as showed in 2018. However, it was significantly higher than full irrigation when experienced water stress at the seedling stage. Different from the pattern of LAI changes the dry matter accumulation almost was not affected by water stress at the seedling stage, moreover it exceeded other treatments at the tuber bulking stage, and kept the highest dry matter accumulation until the harvest (Figure 3).

\subsection{Potato Tuber Yield Under Different Irrigation Treatments}

Among four treatments, DIS and FI produced the highest tuber yield, in 2018 . The marketable tuber $(\geq 150 \mathrm{~g})$ ratio under DIS was significantly higher than that under the other three irrigation treatments. FI produced the most tubers per plant while DII produced the least (Table 6). In 2019 and 2020, the fresh tuber yield showed similar trends as in 2018 (Table 6). 
Table 6. Comparison of tuber yield and its components under different irrigation treatments in 2018, 2019 and 2020. FI, DIS, DII and DIB stand for treatments of full irrigation, deficit irrigation at seedling stage, deficit irrigation at tuber initiation stage and deficit irrigation at tuber bulking stage respectively. Data are means of three independent measurements. Different letters indicate statistical significance at the P=0.05 level within the same column in specific year.

\begin{tabular}{lllll}
\hline Year Cultivar & Irrigation treatments & tuber number per plant & tuber yield (kg/ha) & Ratio of marketable tubers (\%) \\
\hline 2018 & & & & \\
Favorita & FI & $10.8 \mathrm{a}$ & $32353 \mathrm{a}$ & $59.6 \mathrm{~b}$ \\
& DIS & $9.6 \mathrm{~b}$ & $35036 \mathrm{a}$ & $73.9 \mathrm{a}$ \\
& DII & $7.2 \mathrm{c}$ & $23923 \mathrm{~b}$ & $37.6 \mathrm{~b}$ \\
2019 & $9.1 \mathrm{ab}$ & $25741 \mathrm{~b}$ & $57.4 \mathrm{~b}$ \\
Kexin No.1 & DIB & & & $58.2 \mathrm{bc}$ \\
& & $9.4 \mathrm{a}$ & $45449 \mathrm{a}$ & $59.4 \mathrm{ab}$ \\
& FI & $7.4 \mathrm{~d}$ & $38001 \mathrm{c}$ & $62.1 \mathrm{a}$ \\
& DIS2 & $8.5 \mathrm{bc}$ & $46986 \mathrm{a}$ & $53.7 \mathrm{c}$ \\
2020 & DIS1 & $8.2 \mathrm{c}$ & $40391 \mathrm{~b}$ & $54.4 \mathrm{bc}$ \\
Favorita & DII & $8.8 \mathrm{~d}$ & $42262 \mathrm{~b}$ & $39.4 \mathrm{c}$ \\
& DIB & & & $72.9 \mathrm{a}$ \\
2020 & & $10.0 \mathrm{a}$ & $42792 \mathrm{~b}$ & $42.8 \mathrm{~b}$ \\
Kexin No.1 & FI & $9.2 \mathrm{ab}$ & $52902 \mathrm{a}$ & $51.2 \mathrm{c}$ \\
& DIS3 & $7.8 \mathrm{~b}$ & $33372 \mathrm{c}$ & $77.3 \mathrm{a}$ \\
& DIS4 & & $58.2 \mathrm{~b}$ \\
\hline
\end{tabular}

\subsection{Water Use Efficiency Under Different Irrigation Treatments}

Although evapotranspiration (ET) values were different between same treatments in 2018 and 2019, trends were similar among different treatments in two years. Maximum evapotranspiration appeared in full irrigation, followed by DIS and DII treatments, DIB treatment is the least. It exhibited the highest water use efficiency (WUE) under moderate water deficiency (DIS1 and DIS3) at the seedling stage as showed in 2019 and 2020. The results from year 2020 showed that the WUE in severe water deficiency (DIS4) was also higher than that in FI but lower than DIS3 treatment (Table 7).

\section{Discussion}

In order to determine the optimal potato developmental stage conducting deficit irrigation to save water and increase water use efficiency of potato, three-year field experiments were performed to investigate. According to previous studies and local practice, full irrigation amount was ascertained and half of its irrigation water for specific developmental stage was used as deficit treatment in 2018 [5, 23, 26]. By comparing the yield effects under deficit irrigation at different developmental stages, it was found that deficit treatment only at the seedling stage maintained the yield level of full irrigation treatment. The yield was decrease significantly when water deficit at tuber initiation stage and tuber bulking stage (Table 6).

To understand the yield gap among different treatments, root growth, leaf area index (LAI) and dry matter accumulation were investigated under field condition. Root system was analyzed as it is the initial perceiver to sense soil water status. Root elongation and the extension of root surface area were determined by water status, followed by a series of responses at physiological and morphological levels, including water and nutrient absorption and further dry matter accumulation [29-31]. Maintaining primary root elongation has been shown to be an adaptive response to low water potentials in many other plants [31-32]. Actually, root elongation of potato plant is promoted under moderate water stress which was verified by our experiment (Table 4). Elongated root length and enlarged root surface area under moderate water deficiency make up the developed root system at the early developmental stage, which are beneficial for more water absorption and yield formation. The conclusion was testified by three-year yield data although we didn't record root development in 2019 and 2020 (Table 6). Moreover, the increase of root length and surface area under moderate water didn't sacrifice by more dry matter consumption than full irrigation (Table 4). There were no significant differences between FI and DII and DIB treatments in terms of total root length, surface area and volume (Table 4), which is consistent with previous studies [18, 23]. Thus, deficit irrigation at the seedling stage, but not at tuber initiation and bulking stages, is consider to be available for potato production.

Detailed information of root development was analyzed to understand the difference between moderate water deficiency at seedling stage and full irrigation. The results shown that major differences on root length and surface area was at the upper layer $(10-20 \mathrm{~cm}$ ) and lower layers (below $40 \mathrm{~cm}$ ), with no distinct differences at the middle layer between DIS and full irrigation practices (Table 4). The characteristics of root distribution at different layers are consistent with the water dynamics within irrigation cycle, relatively lower water content at $10-20 \mathrm{~cm}$ at the beginning of irrigation cycle $(1 \mathrm{~d}$ after irrigation) and $>40 \mathrm{~cm}$ at the later period of irrigation cycle (4-7d after irrigation) are exhibited (Figure 1). More roots are induced at the regions with lower water content (potential). Soil drying appears earlier at these regions under DIS treatment and induces more root initiation and elongation compared to full irrigation, thus longer root and larger root surface area speculated at DIS treatment. As for the reason of 
water dynamics at different layers during irrigation cycle, it might be attributed to more evapotranspiration and leakage at the upper layer and the lower layer respectively, resulting in its rapid decrease of relative water content (Figure 1).

Although sacrificing the increase of LAI for root development induced by water deficit at the seedling stage, established strong root system lays the foundation for rapid increase of LAI at the later developmental stage. Up to the early tuber initiation stage, the value under moderate water deficiency (DIS, DIS1 and DIS3) is equal to full irrigation control and even surpasses the DII treatment at the later tuber initiation stage. Even under severe water stress condition the LAI is also reached the same level with full irrigation for some year (or cultivar) at later developmental stage (Table. 5). Similar to the changes of LAI, the plant dry matter accumulation under DIS is lower at seedling stage, however the highest accumulation rate is exhibited in DIS among four irrigation treatments, resulting in LAI's surpassing other irrigation treatments at the tuber bulking stage (Figure 2). Well-developed root systems and optimal population leaf area index in DIS treatments are beneficial for yield formation. In our study, DIS in 2018 and DIS1 in 2019, equal to $50-55 \%$ relative water content, did not lower yields compared to FI treatment and increase marketable tuber yield (Table 6). The value of relative water content for yield effects is only suit for sandy loam because the effects varied in different soil texture [23].

Table 7. Effect of different irrigation treatments on water consume and water use efficiency in 2018, 2019 and 2020. FI, DIS, DII and DIB stand for treatments of full irrigation, deficit irrigation at seedling stage, deficit irrigation at tuber initiation stage and deficit irrigation at tuber bulking stage respectively. ET stands for evapotranspiration, WUE stands for water use efficiency. Data are means of three independent measurements. Different letters indicate statistical significance at the $P=0.05$ level within the same column in specific year.

\begin{tabular}{|c|c|c|c|c|}
\hline Year & Cultivar & $\begin{array}{l}\text { Irrigation } \\
\text { treatments }\end{array}$ & ET $(\mathrm{mm})$ & $\begin{array}{l}\text { WUE } \\
(\mathrm{kg} / \mathrm{ha} / \mathrm{mm})\end{array}$ \\
\hline \multirow[t]{4}{*}{2018} & Favorita & FI & 421.01 & $76.85 \mathrm{~b}$ \\
\hline & & DIS & 404.35 & $86.65 \mathrm{a}$ \\
\hline & & DII & 388.81 & $61.53 \mathrm{c}$ \\
\hline & & DIB & 380.73 & $67.61 \mathrm{bc}$ \\
\hline \multirow[t]{5}{*}{2019} & Kexin No.1 & FI & 407.56 & $103.23 \mathrm{~b}$ \\
\hline & & DIS1 & 397.66 & $110.08 \mathrm{a}$ \\
\hline & & DIS2 & 390.13 & $92.04 \mathrm{~d}$ \\
\hline & & DII & 385.75 & $97.00 \mathrm{c}$ \\
\hline & & DIB & 373.01 & $105.79 \mathrm{ab}$ \\
\hline \multirow[t]{6}{*}{2020} & Favorita & FI & 526.23 & $81.32 \mathrm{c}$ \\
\hline & & DIS3 & 346.91 & $152.49 \mathrm{a}$ \\
\hline & & DIS4 & 245.00 & $136.21 \mathrm{~b}$ \\
\hline & Kexin No.1 & FI & 586.73 & $89.54 \mathrm{c}$ \\
\hline & & DIS3 & 484.70 & $125.35 \mathrm{a}$ \\
\hline & & DIS4 & 400.09 & $119.77 \mathrm{~b}$ \\
\hline
\end{tabular}

Although the RWC values are in set range, a little large of fluctuation influenced by rainfall in 2018 and 2019. To eliminate the effects of natural rainfall for the results, the experiment was performed under rain shelter condition in 2020. Based on the results from the previous two years we set DIS3 (50\% RWC) and DIS4 (35\% RWC) treatments. Similar conclusion was obtained although yield still can be maintained at DIS4 for cultivar Kexin No.1 which is more drought tolerance. The results of yield components shown that average tuber weight increase while tuber number per plant decrease in moderate water deficit at seedling stage, marketable tuber yield increase finally, compared with full irrigation (Table 6). Due to less consumption of water at the seedling stage water use efficiency increase in DIS treatments. This suggests that suitable DIS not only increases water use efficiency, which was proved by previous research groups [10, 12,33], but also increases marketable tuber yield.

\section{Conclusions}

Moderate water deficit at the seedling stage, not at the tuber initiation and bulking stages, could increase water use efficiency significantly and maintain tuber yield at the same time. Marketable tuber yield $(>150 \mathrm{~g}$ per tuber) under moderate water deficit at the seedling stage is significantly higher than full irrigation.

Relative soil water content (RWC) can be used as an index to detect and regulate water status, providing reference irrigation quota in potato production finally. Under sandy loam soil condition 50 55\% RWC at the seedling stage is available for the promotion on both water use efficiency and marketable tuber yield, meanwhile, maintain total tuber yield as full water supply. The increase of marketable tuber yield is mainly attributed to its increase of single tuber weight, tuber numbers per plant decrease actually, under DIS treatments.

Root regulation by soil water is the physiological basis of double promotion effects on water efficiency and marketable tuber yield under moderate water deficit at the seedling stage. Under such condition, more roots induced at the upper and lower layers result in larger root surface area at earlier developmental stage, which is beneficial for leaf area increase and dry matter accumulation, tuber yield increase finally, at the later developmental stages.

\section{Acknowledgements}

This work was supported by the Key Project of Inner Mongolia Autonomous Region (2020ZD0005, 2021ZD0005) and National Natural Science Foundation of China (31460321).

\section{References}

[1] Vreugdenhil. D. 2007. Potato Biology and Biotechnology: Advances and Perspectives. pp. 243, Elsevier, Amsterdam, The Netherlands.

[2] FAO (Food and Agriculture Organization of the United Nations). 2012.

http://faostat3.fao.org/faostat-gateway/go/to/download/Q/QC/E.

[3] Paul R., Glenn B., Brian F., Eleanor M., Ingo H., John T., Ankush P., Mark A., Lesley T., Ian K. 2012. Crops that feed the world 8: Potato: are the trends of increased global production sustainable? Food Security 4 (4): 477-508. 
[4] Yuan, B., Kang, Y. 2003. Effects of different irrigation regimes on the growth and yield of drip-irrigated potato. Agr Water Manage 63: 153-167.

[5] Jia L., Wu L., Chen Y., Yu J., Fan M. 2018. Regulation of Water Deficiency to Tuber Development at the Tuber Initiation Stage of Potato. Journal of Inner Mongolia Agricultural University (In Chinese). 039 (002): 13-19.

[6] Monneveux P., Ramírez D. A. and Pino M. T. 2013. Drought tolerance in potato (S. tuberosum, $L$.): Can we learn from drought tolerance research in cereals? Plant Sci. 205 (205--206): 76-86.

[7] Opena, G. B., and Porter, G. A. 1999. Soil management and supplemental irrigation effects on potato. II. Root growth. AgronJ 91: 426-431.

[8] Onder, S., Caliskan, M. E., Onder, D. and Caliskan, S. 2005. Different irrigation methods and water stress effects on potato yield and yield components. Agr Water Manage. 73: 73-86.

[9] Renault, D., Wallender, W. W. 2000. Nutritional water productivity and diets: from"crop per drop" towards "nutrition per drop”. Agr Water Manage. 45: 275-296.

[10] Xie, K., Wang, X. X., Zhang, R., Gong, X., Zhang, S. and Mares, V. 2012. Partial root-zone drying irrigation and water utilization efficiency by the potato crop in semi-arid regions in china. Sci. Hortic. 134, 20-25.

[11] Yactayo W., Ramírez D. A., Gutiérrez R., Mares V., Posadas A. and Quiroz R. 2013. Effect of partial root-zone drying irrigation timing on potato tuber yield and water use efficiency. Agr Water Manage 123: 65- 70.

[12] Kang, S. and Zhang, J. 2004. Controlled alternate partial root-zone irrigation: its physiological consequences and impact on water use efficiency. $J$ Exp Bot. 55, 2437-2446.

[13] Du T., Kang S., Zhang J. and Davies W. J. 2015. Deficit irrigation and sustainable water-resource strategies in agriculture for China's food security. J Exp Bot 66 (8): 2253-2269.

[14] Du T., Kang S., Zhang X. and Zhang J. 2014. China's food security is threatened by the unsustainable use of water resources in North and Northwest China. Food \& Energy Security 3 (1): 7-18.

[15] Zhang J. and Davies W. J. 1989. Sequential responses of whole plant water relations towards prolonged soil drying and the mediation by xylem sap ABA concentrations in the regulation of stomatal behaviour of sunflower plants. New Phytol 113: 167-174.

[16] Zhang J., Schurr U. and Davies W. J. 1987. Control of stomatal behaviour by abscisic acid which apparently originates in roots. $J$ Exp Bot 38: 1174-1181.

[17] Liu, F., Jensen, C. R., Shahanzari, A., Andersen, M. N. and Jacobsen, S. E. 2005. ABA-regulated stomatal control and photosynthetic water use efficiency of potato (Solanum tuberosum L. ) during progressive soil drying. Plant Sci. 168: 831-836.

[18] Liu, F., Shahanzari, A., Andersen, M N., Jacobsen, S. E. and Jensen, C. R. 2006. Physiological responses of potato (Solanum tuberosum $L$.) to partial root zone drying: ABA signalling, leaf gas exchange, and water use efficiency. J Exp Bot. 57: 3727-3735.

[19] Plauborg, F., Abrahamsen, P., Gjettermann, B., Mollerup, M., Bo, V. I. and Liu, F. 2010. Modelling of root aba synthesis, stomatal conductance, transpiration and potato production under water saving irrigation regimes. Agr Water Manage 98 (3): 425-439.
[20] Rodriguez-Falcon, M., Bou, J., and Prat, S. 2006. Seasonal control of tuberization in potato: conserved elements with the flowering response. Annu Rev Plant Biol. 57: 151-180.

[21] Ierna, A., Mauromicale, G. 2006. Physiological and growth response to moderate water deficit of off-season potatoes in a Mediterranean environment. Agr Water Manage. 82: 193-209.

[22] Jensen, C. R., Battilani, A., Plauborg, F., Psarras, G., Chartzoulakis, K., Janowiak, F., Stikic, R., Jovanovic, Z., Li, G., Qi, X., Liu, F., Jacobsen, S. E. and Andersen, M. N. 2010. Deficit irrigation based on drought tolerance and root signaling in potatoes and tomatoes. Agr Water Manage 98: 403-413.

[23] Ahmadi, S. H., Andersen M. N., Plauborg F., Poulsen R. T., Jensen C. R., Sepaskhah A. R., HansenS. 2010. Effects of irrigation strategies and soils on field grown potatoes: Yield and water productivity. Agr Water Manage. 97: 1923-1930.

[24] Iqbal, M. M., Shah, S. M., Mohammad, W. and Nawaz, H. 1999. Field response of potato subjected to water stress at different growth stages. In: Kirda. C., Moutonnet, P., Hera, C., Nielsen, D. R., (eds.), Crop Yield Response to Deficit Irrigation. Kluwer Academic Publishers, The Netherlands, pp: 213-223.

[25] Sparks, D. L., Page, A. L., Johnston, C. T., and Sumner, M. E. 1996. Part 3. Chemical methods. In: Methods of soil analysis Madison: SSSA. 1085-1121.

[26] Wang J., Yang Y., Cai J. and Zhai G. 2018. Experimental Study on the Influence of Working Pressure and Spraying Angle on the Single-hole Spray Characteristics of Micro-sprinkling Hose. Water Saving Irrigation 3: 35-38. (In Chinese).

[27] Marsal J., Mata M., Campo J., Arbones A., Vallverdú X., Girona J., Olivo N. 2008. Evaluation of partial root-zone drying for potential field use as a deficit irrigation technique in commercial vineyards according to two different pipeline layout. Irrigation Science 26: 347-356.

[28] Costa, C., Dwyer, L. M., Hamilton, R. I., Hamel, C., Nantais, L., and Smith, D. L. 2000. A sampling method for measurement of large root systems with scanner-based image analysis. Agron J. 92, 621-627.

[29] Sengupta, D., Kannan, M., and Reddy, A. R. 2011. A root proteomics-based insight reveals dynamic regulation of root proteins under progressive drought stress and recovery in (Vigna radiata L.) Wilczek. Planta. 233, 1111-1127.

[30] Sharp, R. E., Silk, W. K., and Hsiao, T. C. 1988. Growth of the maize primary root at low water potentials: I. Spatial distribution of expansive growth. Plant Physiol. 87, 50-57.

[31] Xu W., Jia L., Shi W., Liang J., Zhou F., Li Q. and Zhang J. 2013. Abscisic acid accumulation modulates auxin transport in the root tip to enhance proton secretion for maintaining root growth under moderate water stress. New Phytol 197: 139-150.

[32] Sharp RE, Poroyko V, Hejlek LG, Spollen WG, Springer GK, Bohnert HJ, Nguyen HT. 2004. Root growth maintenance during water deficits: physiology to functional genomics. $J$ Exp Bot. 55, 2343-2351.

[33] Shahnazari, A., Liu, F., Andersen, M. N., Jacobsen, S. E., and Jensen, C. R. 2007. Effects of partial root-zone drying on yield, tuber size and water use efficiency in potato under field conditions. Field Crop Res. 100, 117-124. 